\title{
A Retrospective Interventional Cohort Study to Assess the Safety and Efficacy of Sandostatin LAR(octreotide) for Treatment of Recurrent and/or Refractory Meningiomas
}

\author{
Daniela Annenelie Bota ( $\sim$ dbota@uci.edu ) \\ University of California, Irvine https://orcid.org/0000-0002-9680-9060 \\ Maya Hrachova \\ University of California Irvine \\ Beverly D. Fu \\ University of California Irvine \\ Xiao-Tang Kong \\ University of California Irvine \\ Gilbert Cadena \\ University of California Irvine \\ Frank P.K. Hsu \\ University of California Irvine \\ John Billimek \\ University of California Irvine \\ Manisha Dandekar \\ University of California Irvine
}

\section{Research article}

Keywords: Recurrent progressive meningioma, Somatostatin, Octreotide, Sandostatin LAR

Posted Date: June 21st, 2019

DOI: https://doi.org/10.21203/rs.2.10502/v1

License: (c) (1) This work is licensed under a Creative Commons Attribution 4.0 International License. Read Full License 


\section{Abstract}

Background Meningiomas are the most common adult primary intracranial tumors in the United States. Despite, high recurrence rate of atypical and malignant subtypes, there is no approved drug indicated specifically for meningioma. Majority of meningiomas exhibit high density (70\%) of somatostatin receptors subtypes, and somatostatin analogs have been under close investigation as a potential treatment option for management of progressive or recurrent meningiomas. The aim of this study was to evaluate efficacy and safety of Sandostatin LAR (octreotide) in patients with progressive and/or recurrent meningioma. Methods A total of 44 patients $\geq 18$ years old were included in retrospective chart review. They were diagnosed with meningioma and underwent therapy with Sandostatin LAR (octreotide) from 01/01/10 until 06/01/17 at the University of California, Irvine. Six months progression free survival (PFS6) was defined as a primary endpoint, and the overall survival (OS) was a secondary endpoint along with safety and toxicity. Results The PFS6 months for all tumor grades was $80.6 \%$. The OS for 6 months, 1 year, and 3 years for all WHO grades was $94.9 \%$ (95\% confidence interval [Cl]: 0.88-1.00), 88.4\% (95\% Cl: 0.78-0.99), and 67.2\% (95\% Cl: 0.36-0.99) respectively. Median TTP for WHO grade I, II and III was 3.1, 2.40, and 0.20 years respectively. Sandostatin LAR (octreotide) was well tolerated. Conclusions This is the largest reported retrospective analysis of meningioma patients treated with Sandostatin LAR (octreotide) and suggests that this treatment has minimal to no adverse events and could prolong overall survival and progression free survival.

\section{Importance Of The Study:}

This study is the largest study to date that provides additional evince to support current treatment guideline for management of progressive and/or recurrent meningiomas by the National Comprehensive Cancer Network (NCCN) [1]. Additional prospective, larger scale randomized trials are needed to validate effectiveness of Sandostatin LAR (octreotide) in meningioma. Furthermore, our study provides a diverse patient population, and includes Hispanics (25.5\%) and Asians (22.7\%).

\section{Introduction}

Meningiomas are dural-based tumors that arise from an arachnoid layer or meningothelial cells. They are the most common primary adult CNS tumors, and account for $36.8 \%$ of all primary brain tumors [2]. Most meningiomas are histologically classified as World Health Organization (WHO) grade I tumors (benign, 81.3\%) with an indolent course. WHO grade II (atypical, 16.9\%) and WHO grade III (anaplastic, $1.7 \%$ ) tumors classified as high-grade tumors and known to be more aggressive with increased risk of recurrence [3].

If indicated based on tumor size or tumor progression, patients with WHO grade I meningiomas undergo complete surgical resection [4]. Approximately $5 \%$ of completely resected benign meningiomas, $30 \%$ of partially resected benign meningiomas and $40 \%$ of atypical meningiomas recur within 5 years after surgery[5]. Despite surgical resection and radiation therapy that is standard of care for WHO grade II and III meningiomas, patients have higher recurrence risk of $29-52 \%$ and $50-94 \%$, respectively [6]. Depending on tumor location, invasion of surrounding structures, age and medical comorbidities of the patient, surgical intervention is not always possible. Chemotherapy or biologics are then considered as an alternate treatment option. However, there is no FDA approved drug indicated specifically for meningioma, and patients with atypical, anaplastic, recurrent or invasive meningiomas are often left with limited options.

The National Comprehensive Cancer Network (NCCN) guideline identified three drug classes that showed some benefits for treatment of meningioma in retrospective analysis or small phase II trials: vascular endothelial growth factor (VEGF) signaling pathway inhibitors, alpha-interferons, and somatostatin receptor agonists [1,7]. Since the majority of meningiomas exhibit a high density $(70 \%)$ of somatostatin receptors subtypes (SSTR1-SSTR5), it is not surprising that somatostatin analogs have been under close investigation as a potential treatment option $[8,9]$.

Somatostatin is an a cyclic tetradecapeptide hormone that is produced in hypothalamus and released into systemic circulation, where it exhibits its exocrine and endocrine inhibitory functions by targeting pituitary, pancreas and gastrointestinal tract [10]. It also has been implicated in the induction of apoptosis and inhibition of angiogenesis [11]. Since naturally occurring somatostatin has a short half-life, somatostatin analogs were developed to achieve a longer half-life (lanreotide, pasireotide, and octreotide).

Sandostatin LAR (octreotide) is another long acting somatostatin analogue approved by the FDA for treatment of acromegaly, severe diarrhea/flashing episodes associated with metastatic carcinoid tumors, and vasoactive intestinal peptide (VIP) secreting tumors [12]. Given that Sandostatin LAR (octreotide) was shown to significantly decrease cell proliferation in $88 \%$ of meningiomas with more prominent inhibition in a group expressing a high level of SSTR2a, one of the most frequently expressed receptors in meningiomas, investigative work was initiated to assess its efficacy for treatment of meningiomas $[8,13]$. 
A prospective pilot study showed that $31 \%$ of patients with recurrent meningiomas demonstrated a partial radiographic response and $44 \%$ achieved progression free survival (PFS) at 6 months with minimal side effects after undergoing treatments with Sandostatin LAR (octreotide) [14]. Even though a phase II study conducted to evaluate the efficacy and safety of Sandostatin LAR (octreotide) did not demonstrate a significant benefit, 2 patients experienced prolonged stability of previously progressive tumors [15]. Studies that investigated the effect of Sandostatin LAR (octreotide) in patients with a progressive benign residual or recurrent meningioma of the skull base, showed that somatostatin analog can arrest progression and stabilized disease [16].

Numerous case reports and clinical studies highlighted potential benefit of Sandostatin LAR (octreotide) for treatment of meningioma, but due to small sample size, no statistical significance was achieved. Thus, our retrospective interventional cohort study with a bigger sample size provides supporting evidence to consider Sandostatin LAR (octreotide) as a potential candidate for meningioma based treatment taken into an account its tolerability and safety profile.

\section{Materials And Methods}

The following study was a retrospective interventional cohort analysis conducted at the University of California Medical Center (UCIMC) between January 2010 and June 2017. The study cohort consisted of patients with recurrent and/or progressive WHO grade I, II or III meningiomas who received treatment with Sandostatin LAR (octreotide). All information related to patients' demographics, cancer type, response to treatment, therapies previously received, and Karnofsky performance scores (KPS) were collected [17]. The primary objective of this study was to determine efficacy of Sandostatin LAR (octreotide) in patients with recurrent and/or progressive meningiomas. Six months PFS6 was defined as a primary endpoint, and OS was a secondary endpoint. Safety and toxicity of Sandostatin LAR (octreotide) were assessed as well.

\section{Patients Eligibility}

Patients were required to be $\geq 18$ years old with recurrent and/or progressive meningioma expressing sandostatin receptors confirmed by positive ${ }^{111}$ Indium $\left({ }^{111}\right.$ In) - octreotide positron emission tomography (PET) or positive immunohistochemistry analysis. Patients were determined to be poor candidates for surgical resection, stereotactic radiosurgery or radiation therapy based on tumor location, increased risk factors for postoperative morbidity and mortality, or individual preference for noninvasive approach, or were shown to have recurrence despite surgical or radiation therapy. There was no limit on the number of prior surgeries, radiation or radiosurgery treatments. Patients were excluded if metastatic lesions were found on octreotide PET scan or informed consent was not obtained.

\section{Treatment Plan}

In order to confirm meningioma and its response to treatment with Sandostatin LAR (octreotide) the vast majority of patients underwent a

${ }^{111}$ In-octreotide PET scan. For patients who were unable to undergo a ${ }^{1111}$ In-octreotide PET scan, meningioma was confirmed by immunohistochemical analysis. A MRI or CT scan was done prior to first drug administration, and was repeated every 2 to 3 months thereafter for an evaluation of tumor status. Patients received deep intragluteal injections of Sandostatin LAR (octreotide) monthly, and were treated until disease progression or intolerability. The dose of Sandostatin LAR (octreotide) was gradually increased from $30 \mathrm{mg}$ to 40 $\mathrm{mg}$ per injection if tolerated. Patients were followed for any adverse reactions to the drug. The treatment was stopped if the patient met any of the following criteria: MRI or CT showed tumor progression, serious adverse events, physician discretion, patient's choice to discontinue treatment, death, or lost to follow up. The institutional review board approved the study, and all patients that participated provided written informed consent.

\section{Statistical Methods}

Data was analyzed by using the IBM SPSS statistical program package (PAWS statistics v18.0). Data was grouped into categories based on demographics, WHO tumor grades, KPS scores and treatment characteristics, and analyzed using descriptive statistics. The PFS was calculated from the date of initial treatment with Sandostatin LAR (octreotide) until the date of death or disease progression. Patients who did not experience disease progression were censored. The OS was estimated from the date of initial treatment with Sandostatin LAR (octreotide) to the date of death or last known date to be alive. Subjects that have not died were censored at the last known date to be alive. Survival curves were estimated by generating Kaplan-Meier methods. PFS and OS were compared between WHO tumor grades, ethnicities and races. The log rank test was used to compare the survival distributions of the groups. P-value $<0.05$ for all analyses was 
considered significant. Best radiographic response was determined based on 2010 the Response Assessment in Neuro-Oncology (RANO) Working Group [18]. Results from our treatment group were compared to results from previous published studies using Sandostatin LAR (octreotide) for treatment of meningioma and compared to other studies using interferon-alpha, bevacizumab, sunitinib, vatalanib, imatinib, imatinib/ hydroxyurea, and erlotinib/ gefitinib.

\section{Safety and Toxicity}

Adverse events were reported by patients and/or providers when clinically significant abnormal laboratory, or physical examination findings were identified requiring intervention. Adverse events were recorded from the first date of Sandostatin LAR (octreotide) administration until death or 12 months follow up. The relationship of the adverse event to Sandostatin LAR (octreotide) was also evaluated. It was considered to be a related event when there was an evidence to suggest the relationship between the drug and the adverse event. An unrelated event was thought to be an adverse event, possibly caused by an underlying disease or biologically improbable event. Safety results were evaluated via descriptive statistics to identify frequency, type, and severity of adverse events.

Treatment related toxicities were evaluated using the Common Terminology Criteria for Adverse Events (CTCAE) version 4.03 [19]. All patients who received Sandostatin LAR (octreotide) were evaluable for toxicity, and toxicity results were then compared to other clinical studies.

\section{Results}

\section{Patients Characteristics}

A total of 44 patients with recurrent or progressive WHO grade I (75.0\%), II (11.4\%) and III (13.6\%) meningiomas were enrolled in this study, including 5 with atypical and 6 with anaplastic meningiomas (Table 1). The majority of patients were females (70.5\%) who identified as White (38.6\%), Hispanic (25.0\%) or Asian (22.7\%). Median age was 65 years old. Median KPS score was 80 . Median number of Sandostatin LAR (octreotide) injections was 8. Evaluation of prior treatments identified that $75.0 \%$ of patients with all tumor grades had surgical resections, $45.4 \%$ had radiation therapy while $13.6 \%$ underwent chemotherapy. Analysis of prior recurrences identified 12 patients with WHO grade I tumors who had no prior recurrences, 7 patients with one recurrence, 10 patients with two recurrences and 4 patients with three or more recurrences. All patients with WHO grade II and III meningiomas were noted to have two or more recurrences.

\section{Toxicity}

Toxicity data is reported for all 44 patients (Table 2). In general, therapy with Sandostatin LAR (octreotide) was well tolerated. No grade 4 or 5 adverse events were observed. Sandostatin LAR (octreotide) treatments were discontinued in two patients after they experienced significant adverse events. One patient developed cholelitiasis complicated by pancreatitis identified as grade 3 adverse event. The other patient experienced vomiting that was defined as grade 2 event. The majority of grade 2 adverse events included diarrhea (11.4\%), headache (6.8\%), nausea (4.5\%) and abdominal pain (4.5\%). Patients more frequently experienced grade 1 events with diarrhea (27.3\%) and headache $(27.3 \%)$ being most common side effects.

\section{Response and Outcome}

Analysis indicated that the median PFS for all tumor grades was 3.0 years (95\% Cl: 2.20-3.80), PFS6 80.6\% (95\% Cl: 0.68-0.93), PFS12 71.9\% (95\% Cl: 0.58-0.86), and PSF36 46.2\% (95\% Cl: 0.21-0.72) (Table 3). The median PFS for WHO grade I meningiomas was 3.1 years (95\% Cl: 2.80-3.40), PFS6 89.8\% (95\% Cl: 0.79-1.00), PFS12 82.0\% (95\% Cl: 0.67-0.97), and PSF36 61.5\% (95\% Cl: 0.25-0.98). The median PFS for WHO grade II meningiomas was 2.4 years (95\% Cl: 1.40-3.30), PFS6 80.0\% (95\% Cl: 0.45-1.00), PFS12 80.0\% (95\% Cl: 0.45-1.00), and PSF36 30.00\% (95\% Cl: 0.00-0.77). The median PFS for WHO grade III meningiomas was 0.2 years (95\% Cl: $0.05-0.36)$, patients in this group did not survive past 6 months. The log rank test had a value of $p<0.001$ which means that there was a statistically significant difference in PFS between the WHO tumor grade groups. Kaplan-Meier curves were generated to analyze the overall PFS and PFS stratified by WHO tumor grade (Fig. 1A, Fig. 1B).

The median OS for all tumor grades has not been yet reached, thus it could not be reported (Table 4). There was a low event rate in which half of patients remained alive. The median OS for WHO grade III meningioma was 1.0 (95\% Cl: 0.45-1.56). The OS for all tumor grades at 
6 months was $94.9 \%(95 \% \mathrm{Cl}: 0.88-1.00), 88.4 \%$ (95\% Cl: $0.78-0.99)$ at 1 year, and $67.2 \%(95 \%$ Cl: $0.36-0.99)$ at 3 years. The 0 s was also calculated for each WHO tumor grade at 6 months, 1 year and 3 years. The OS for I, II, and III at 6 months were $96.6 \%$ (95\% Cl: 0.90-1.00), $100 \%$, and $83.3 \%$ (95\% Cl: 0.54-1.00) respectively. At 1 year, the OS for WHO grade I was $96.6 \%$ (95\% Cl: 0.90-1.00), 100\% for WHO grade II and for WHO grade III was 62.5\% (95\% Cl: 0.21-1.00). The OS at 3 years for WHO grade I was 77.2\% (95\% Cl: 0.43-1.00). Kaplan Meier curves were generated to show OS and OS stratified by WHO grade (Fig. 1C, Fig. 1D).

\section{Discussion}

Currently, there are no FDA approved therapies for management of surgically inaccessible or radiation-refractory recurrent meningiomas. In 2018, the Central Nervous System NCCN guideline recommended somatostatin analogues as valuable therapeutic options for management of progressive or recurrent meningiomas [1]. These recommendations were derived from limited studies evaluating various somatostatin analogues (somatostatin, pasireotide, octreotide and Sandostatin LAR). Our study, on the other hand, is the largest reported retrospective analysis to date of meningioma patients with recurrent and/or progressive disease treated with Sandostatin LAR (octreotide).

Comprehensive review of our study and previously reported data are summarized in Table 5.0. The results of our study were compatible or showed significant improvement from prior investigations. Specifically, PFS6 in our study for all tumor grades was $80.6 \%$ while prior studies reported PFS6 in $32.0 \%$ to $44.4 \%$ range. The OS for all tumor grades has not been achieved in our study, while other investigations reported OS range from 7.5 to 34.2 months. Median KPS status in all studies ranged from 80 to 85 . The prospective pilot trial conducted by Chamberlain, et al. included 16 patients with low and high grade recurrent meningiomas who received treatment with Sandostatin LAR (octreotide) [14]. Analysis indicated PFS6 of 44\%, median TTP of 5 months and median OS of 7.5 months with minimal toxicity. The phase II study by Johnson, et al. evaluated 12 patients with all tumor grades reported median TTP as 4.25 months and median OS as 32.4 months [15]. Schulz, et al., evaluated 13 patients with WHO tumor grade I meningiomas, and only median TTP was reported as 24 months [16]. Simo, et al., conducted phase II trial on patients with high-grade meningiomas who received subcutaneous octreotide injections every 28 days and reported PFS6 as 44.4\%, median TTP as 4.23 months, and median OS as 18.7 months [20]. Norden, et al., showed no radiographic response to therapy with pasireotide LAR (SOM230C) on 28 patients with recurrent meningiomas of all tumor grades, PFS6 as $32 \%$ and median TTP as 4.5 months, but overall OS was not reached [21]. Overall, our data shows longer PFS compared to the other clinical studies. Reported toxicities were consistent across clinical studies with diarrhea, nausea, vomiting and transminities being the most common events. Prior studies had less than 25 patients that resulted in low statistical power.

Our clinical study provides additional evidence to support the rationale for a larger phase study to assess the efficacy of Sandostatin LAR (octreotide). Compared to other therapeutics, octreotide Sandostatin LAR (octreotide) had longer median PFS, PFS6 and safer profile (Table 6.0). There were no observed CTCAE grade 4 or grade 5 adverse events. There was only one grade 3 adverse event in our study that identified the patient who was hospitalized with pancreatitis after developing cholelithiasis. Sandostatin LAR (octreotide) was subsequently discontinued in this patient. Erlotinib demonstrated a favorable safety profile compared to all the other drugs, however, median PFS was lower than patients who received Sandostatin LAR (octreotide).

It is important to note, that the CNS NCCN guideline classifies somatostatin analogue, as a level 2A category for patients with progressive recurrent meningioma while interferon alpha, sunitinib and bevacizumab, and everolimus combination were given $2 \mathrm{~B}$ category [1]. Category $2 \mathrm{~A}$ evidence is based on lower-level evidence with uniform NCCN consensus that the intervention is appropriate, while category $2 \mathrm{~B}$ evidence that is also based on lower level of evidence was only granted experts consensus. These recommendations are not surprising, as scientific literature review indicates that somatostatin analogues including Sandostatin LAR (octreotide) are better tolerated therapies with good efficacy as evidenced by longer PSF and PFS6.

Specifically, phase II clinical trial that included 36 patients with high-grade meningioma who received sunitibin showed efficacy of that treatment based on PFS6 of 42\%, median PFS of 5.2 months and median OS of 24.6 months [22]. However, considerable toxicity was observed with 1 grade 5, 1 grade 4 and 2 grade 3 intratumoral hemorrhages, 1 grade 4 and 1 grade 3 thrombic microangiopathy attributed to known side effect profile of VEGF inhibitors. By comparison all studies on somatostatin analogues including this report indicate well tolerability and minimal side effects with diarrhea being the most commonly reported side effect.

The phase II clinical study evaluated efficacy of combination of everolimus and bevacizumab in 17 patients with progressive recurrent meningiomas (WHO tumor grade I,II and III) showed that this regiment was well tolerated, and produced stable diseases in $88 \%$ of patients with median PFS as 22 months, PFS as $69 \%$ and median OS of 23.8 months [23]. No grade 5 or grade 4 toxicities were reported, but four patients (22\%) discontinued treatment due to grade 3 toxicities such as proteinurea, colitis and thrombocytopenia. Important to note, that since the sample size was small, additional work in indicated. In comparison, our study is the largest study that included 44 patients providing more conclusive results. 
A retrospective case series evaluated treatment with interferon alpha for patients with high grade meningiomas that showed progression after surgery, radiotherapy, or prior systemic chemotherapy [24]. The study revealed the median PFS of 12 weeks and PFS6 of 17\% without radiographical response and moderate toxicity. Unfortunately, given that overall PFS and PFS6 were below benchmark criteria of PFS of $26 \%$ for atypical and malignant meningiomas proposed by the Response Assessment in Neuro-Oncology (RANO) Working Group 2014, it appears to be an unlikely candidate for use for treatment of progressive recurrent meningiomas [25].

Thus, based on available clinical data, Sandostatin LAR (octreotide) should be given preferential choice for managing patients with progressive and/or recurrent meningiomas. Nevertheless, this was a retrospective study with several limitations, imposed by the type of the study. Comparison of Sandostatin LAR (octreotide) to other therapeutics were hindered, as all the studies have different methodologies, size, patient population or objectives. In addition, our study did not include a control, and prior reported studies were used for comparison. Despite the stated limitations, our study is the largest study to date that provides rationale and supports further investigation of Sandostatin LAR (octreotide) for the treatment of progressive or recurrent meningiomas. Additional prospective, larger scale randomized trials are needed to validate the effectiveness of Sandostatin LAR (octreotide) in meningioma.

\section{References}

1. NCCN Guidelines for Central Nervous System Cancers V.1.2018. Available at https://www.nccn.org/professionals/physician_gls/default.aspx. Accessed 18 July 2018.

2. Ostrom QT, Gittleman H, Liao P, et al. CBTRUS Statistical Report: Primary brain and other central nervous system tumors diagnosed in the United States in 2010-2014. Neuro-Oncology. 2017;19(Suppl 5):v1-v88.

3. Louis DN, Perry A, Reifenberger G, et al. The 2016 World Health Organization Classification of Tumors of the Central Nervous System: a summary. Acta Neuropathol. 2016;131:803-20.

4. Apra C, Peyre M, Kalamarides M. Current treatment options for meningioma. Expert Rev Neurother. 2018;18:241-9.

5. Meningioma brochure. Available at http://www.abta.org/secure/meningioma-brochure.pdf. Accessed 18 July 2018.

6. Louis DN, Ohgaki H, Wiestler OD, et al. The 2007 WHO Classification of Tumors of the Central Nervous System. Acta Neuropathologica. 2007;114(2):97-109.

7. Karsy M, Guan J, Cohen A, et al. Medical Management of Meningiomas: Current Status, Failed Treatments, and Promising Horizons. Neurosurg Clin N Am. 2016; 27(2): 249-60.

8. Schulz S, Pauli SU, Schulz S, et al. Immunohistochemical determination of five somatostatin receptors in meningioma reveals frequent overexpression of somatostatin receptor subtype sst2A. Clin Cancer Res. 2000;6:1865-74.

9. Reubi JC, Schaer JC, Waser B, et al. Expression and localization of somatostatin receptor SSTR1, SSTR2, and SSTR3 messenger RNAs in primary human tumors using in situ hybridization. Cancer Res. 1994;54(13):3455-3459.

10. Lamberts SW, van der Lely AJ, de Herder WW, et al. Octreotide. N Engl J Med. 1996;334(4):246-254.

11. Pyronnet S, Bousquet C, Najib S, et al. Antitumor effects of somatostatin. Mol Cell Endocrinol. 2008;286:230 - 237.

12. Highlights of prescribing information. Sandostatin LAR. Available at https://www.accessdata.fda.gov/drugsatfda_docs/label/2008/021008s021lbl.pdf. Accessed 18 July 2018.

13. Graillon T, Romano D, Defilles $C$, et al. Octreotide therapy in meningiomas: in vitro study, clinical correlation, and literature review. $J$ Neurosurg.2016. pp. 1-10.

14. Chamberlain MC, Glantz MJ, Fadul CE. Recurrent meningioma: salvage therapy with long-acting somatostatin analogue. Neurology. 2007; 69(10): 969-73.

15. Johnson DR, Kimmel DW, Burch PA, et al. Phase II study of subcutaneous octreotide in adults with recurrent or progressive meningioma and meningeal hemangiopericytoma. Neuro Oncol. 2011;13:530-5.

16. Schulz C, Mathieu R, Kunz U, et al. Treatment of unresectable skull base meningiomas with somatostatin analogs. Neurosurg Focus. 2011(5); 30(5): E11.

17. Schag CC, Heinrich RL, Ganz PA. Karnofsky performance status revisited: Reliability, validity, and guidelines. J Clin Oncology. 1984; 2:187-193.

18. Wen PY, Macdonald DR, Reardon DA, et al. Updated response assessment criteria for high-grade gliomas: response assessment in neuro-oncology working group. J. Clin. Oncol. 2010; 28(11): 1963-72.

Common Terminology Criteria for Adverse Events (CTCAE) v 4.03. Available at 
https://ctep.cancer.gov/protocolDevelopment/electronic_applications/ctc.htm. Accessed 18 July 2018.

19. Simó M, Argyriou AA, Macià M, et al.Recurrent high-grade meningioma: a phase II trial with somatostatin analogue therapy. Cancer Chemother. Pharmacol. 2014;73(5), 919- 923.

20. Norden AD, Ligon KL, Hammond SN, et al.Phase II study of monthly pasireotide LAR (SOM230C) for recurrent or progressive meningioma. Neurology. 2015; 84(3), 280-286. 『

21. Kaley TJ, Wen P, Schiff D, et al. Phase II trial of sunitinib for recurrent and progressive atypical and anaplastic meningioma. NeuroOncol. 2015;17(1), 116-121.

22. Shih KC, Chowdhary S, Rosenblatt $\mathrm{P}$, et al. A phase II trial of bevacizumab and everolimus as treatment for patients with refractory, progressive intracranial meningioma. J Neuro Oncol. 2016;129:281-8.

23. Chamberlain MC. IFN- alpha for recurrent surgery- and radiation-refractory high-grade meningioma: a retrospective case series. CNS Oncol. 2013;2(3), 227-235. 『

24. Kaley T, Barani I, Chamberlain M, et al. Historical benchmarks for medical therapy trials in surgery-and radiation-refractory meningioma: a RANO review. Neuro-Oncology. 2014;16(6):829-840.

25. Nayak L, Iwamoto FM, Rudnick JD, et al.Atypical and anaplastic meningiomas treated with bevacizumab. J. Neurooncol. 2012;109(1), 187-193.

26. Lou E, Sumrall AL, Turner S, et al.Bevacizumab therapy for adults with recurrent/progressive meningioma: a retrospective series. J. Neurooncol. 2012;109(1), 63- 70.

27. Nunes FP, Merker VL, Jennings D, et al.Bevacizumab treatment for meningiomas in NF2: a retrospective analysis of 15 patients. PloS One. 2012;8(3), e59941.

28. Alanin MC, Klausen C, Caye-Thomasen P, et al.Effect of bevacizumab on intracranial meningiomas in patients with neurofibromatosis type 2 - a retrospective case series. Int. J. Neurosci. 2016;126(11):1002-6.

29. Wen PY, Yung WKA, Lamborn KR, et al.Phase II study of imatinib mesylate for recurrent meningiomas (North American Brain Tumor Consortium study 01-08). Neuro-Oncol. 2009;11(6), 853-860.

30. Horak P, Wöhrer A, Hassler M, et al. Imatinib mesylate treatment of recurrent meningiomas in preselected patients: a retrospective analysis. J. Neurooncol. 2012;109(2), 323-330.

31. Reardon DA, Norden AD, Desjardins A, et al.Phase II study of Gleevec $®$ plus hydroxyurea (HU) in adults with progressive or recurrent meningioma. J. Neurooncol. 2012;106(2), 409-415.

32. Raizer JJ, Grimm SA, Rademaker A, et al. A phase II trial of PTK787/ZK 222584 in recurrent or progressive radiation and surgery refractory meningiomas. J. Neurooncol. 2014;117(1), 93-101.

33. Kaley TJ, Wen P, Schiff D, et al. Phase II trial of sunitinib for recurrent and progressive atypical and anaplastic meningioma. NeuroOncol. 2015,17(1), 116-121.

34. Norden AD, Raizer JJ, Abrey LE, et al. Phase II trials of erlotinib or gefitinib in patients with recurrent meningioma. J. Neurooncol. 2010;96(2), 211-217.

35. Chamberlain MC, Glantz MJ. Interferon-alpha for recurrent World Health Organization grade 1 intracranial meningiomas. Cancer. 2008;113(8), 2146-2151.

36. Chamberlain MC. IFN- \pm for recurrent surgery- and radiation-refractory high-grade meningioma: a retrospective case series. CNS Oncol. $2013,2(3), 227-235$.

\section{Tables}

Table 1. Patient Demographic and Clinical Characteristics $(n=44)$. 


\begin{tabular}{|c|c|c|c|c|}
\hline Characteristics & \multicolumn{4}{|l|}{ All Patients } \\
\hline Median Age (years) (range) & \multicolumn{4}{|l|}{$65(35-90)$} \\
\hline Male, No. (\%) & \multicolumn{4}{|l|}{$13(29.5)$} \\
\hline Female, No. (\%) & \multicolumn{4}{|l|}{$31(70.5)$} \\
\hline \multicolumn{5}{|l|}{ Ethnicity/Race, No. (\%) } \\
\hline . White & \multicolumn{4}{|l|}{$17(38.6)$} \\
\hline Hispanic & \multicolumn{4}{|l|}{$11(25.0)$} \\
\hline Asian & \multicolumn{4}{|l|}{$10(22.7)$} \\
\hline Pacific Islander & \multicolumn{4}{|l|}{$2(4.5)$} \\
\hline Black or African American & \multicolumn{4}{|l|}{$2(4.5)$} \\
\hline Iranian & \multicolumn{4}{|l|}{$2(4.5)$} \\
\hline Median number of Sandostatin LAR (octreotide acetate) injections & \multicolumn{4}{|c|}{8 treatments $(1-25)$} \\
\hline \multicolumn{5}{|l|}{ KPS Score at Baseline, No. (\%) } \\
\hline 50 & \multicolumn{4}{|l|}{$1(2.3)$} \\
\hline 60 & \multicolumn{4}{|l|}{$2(4.5)$} \\
\hline 70 & \multicolumn{4}{|l|}{$9(20.5)$} \\
\hline 80 & \multicolumn{4}{|l|}{$15(34.1)$} \\
\hline 90 & \multicolumn{4}{|l|}{$13(29.5)$} \\
\hline 100 & \multicolumn{4}{|l|}{$4(9.1)$} \\
\hline Median & \multicolumn{4}{|l|}{80} \\
\hline \multicolumn{5}{|l|}{ WHO Tumor Grade No. (\%) } \\
\hline 1 & \multicolumn{4}{|l|}{$33(75.0)$} \\
\hline 2 & \multicolumn{4}{|l|}{$5(11.4)$} \\
\hline 3 & \multicolumn{4}{|l|}{$6(13.6)$} \\
\hline \multirow[t]{2}{*}{ Prior Treatments No. (\%) } & WHO Grade 1 & WHO Grade 2 & WHO Grade 3 & All Grades \\
\hline & $25(56.8)$ & $3(6.8)$ & $5(11.4)$ & $33(75.0)$ \\
\hline Resection & $5(11.4)$ & $1(2.3)$ & $0(0)$ & $6(13.6)$ \\
\hline Chemotherapy & $14(31.8)$ & $1(2.3)$ & $5(11.4)$ & $20(45.4)$ \\
\hline \multicolumn{5}{|l|}{ Radiation therapy } \\
\hline \multirow[t]{2}{*}{ Previous Recurrences No. (\%) } & WHO Grade 1 & WHO Grade 2 & WHO Grade 3 & All Grades \\
\hline & $12(27.3)$ & $0(0)$ & $0(0)$ & $12(27.3)$ \\
\hline 0 & $7(15.9)$ & $0(0)$ & $0(0)$ & $7(15.9)$ \\
\hline 1 & $10(22.7)$ & $3(6.82)$ & $2(4.5)$ & $15(34.1)$ \\
\hline 2 & $4(9.1)$ & $2(4.5)$ & $4(9.1)$ & $10(22.7)$ \\
\hline $3 \leq$ & & & & \\
\hline
\end{tabular}


Table 2. Treatment Related CTCAE Adverse Events $(n=44)$.

\begin{tabular}{|c|c|c|c|c|}
\hline Adverse Events & $\begin{array}{l}\text { CTCAE Grade } 1 \\
\text { No. (\%) }\end{array}$ & $\begin{array}{l}\text { CTCAE Grade } 2 \\
\text { No. (\%) }\end{array}$ & $\begin{array}{l}\text { CTCAE Grade } 3 \\
\text { No. (\%) }\end{array}$ & Total No. (\%) \\
\hline Diarrhea & $12(27.3)$ & $5(11.4)$ & 0 & $17(38.6)$ \\
\hline Loose stools & $5(11.4)$ & 0 & 0 & $5(11.4)$ \\
\hline Headache & $12(27.3)$ & $3(6.8)$ & 0 & $15(34.1)$ \\
\hline Local pain & $7(15.9)$ & 0 & 0 & $7(15.9)$ \\
\hline Flu like symptoms & $3(6.8)$ & $1(2.3)$ & 0 & $4(9.1)$ \\
\hline Weakness & $1(2.3)$ & $1(2.3)$ & 0 & $2(4.5)$ \\
\hline Palmar redness & $1(2.3)$ & 0 & 0 & $1(2.3)$ \\
\hline Chills & $1(2.3)$ & 0 & 0 & $1(2.3)$ \\
\hline Sweats & $1(2.3)$ & 0 & 0 & $1(2.3)$ \\
\hline Arthralgia & $1(2.3)$ & 0 & 0 & $1(2.3)$ \\
\hline Nausea/vomiting & $3(6.8)$ & $2(4.5)$ & 0 & $5(11.4)$ \\
\hline Abdominal pain & $2(4.5)$ & $2(4.5)$ & 0 & $4(9.1)$ \\
\hline Insomnia & $3(6.8)$ & $1(2.3)$ & 0 & $4(9.1)$ \\
\hline Dizziness & $4(9.1)$ & 0 & 0 & $4(9.1)$ \\
\hline Constipation & $9(20.5)$ & $1(2.3)$ & 0 & $10(22.7)$ \\
\hline Anxiety & $0(0)$ & $1(2.3)$ & 0 & $1(2.3)$ \\
\hline Fatigue & $4(9.1)$ & 0 & 0 & $4(9.1)$ \\
\hline Pancreatitis & 0 & 0 & $1(2.3)$ & $1(2.3)$ \\
\hline Cholelithiasis & 0 & 0 & $1(2.3)$ & $1(2.3)$ \\
\hline Abdominal bloating & $1(2.3)$ & 0 & 0 & $1(2.3)$ \\
\hline
\end{tabular}

Table 3. Median Progression Free Survival and Progression Free Survival at 6 months, 1 year, and 3 years ( $n=44)$. 


\begin{tabular}{|llllll|}
\hline PFS & WHO Grade 1 & $\mathbf{( C l ~ 9 5 \% )}$ & WHO Grade 2 (Cl 95\%) & WHO Grade 3 (Cl 95\%) & ALL (Cl 95\%) \\
\hline 6 months & $89.8 \%(0.79-1.00)$ & $80.0 \%(0.45-1.00)$ & $33.3 \%(0.00-0.71)$ & $80.6 \%(0.68-0.93)$ \\
\hline 1 year & $82.0 \%(0.67-0.97)$ & $80.0 \%(0.45-1.00)$ & - & $71.9 \%(0.58-0.86)$ \\
\hline 3 years & $61.5 \%(0.25-0.98)$ & $30.0 \%(0.00-0.77)$ & - & $46.2 \%(0.21-0.72)$ \\
\hline Median PFS & WHO Grade 1 & $\mathbf{( C l ~ 9 5 \% )}$ & WHO Grade 2 (Cl 95\%) & WHO Grade 3 (Cl 95\%) & ALL (Cl 95\%) \\
\hline Median & 3.1 years & 2.4 years & 0.2 years $\quad(0.05-0.36)$ & 3.0 years & $(2.2-3.8)$ \\
& $(2.8-3.4)$ & $(1.4-3.3)$ & & & \\
\hline
\end{tabular}

Table 4. Median Overall Survival and Overall Survival at 6 months, 1 year, and 3 years $(n=44)$.

\begin{tabular}{|lllll|}
\hline OS & WHO Grade 1 (Cl 95\%) & WHO Grade 2 (Cl 95\%) & WHO Grade 3 (Cl 95\%) & ALL (Cl 95\%) \\
\hline 6 months & $96.6 \%(0.90-1.00)$ & $100 \%$ & $83.3 \%(0.54-1.00)$ & $94.9 \%(0.88-1.00)$ \\
\hline year & $96.6 \%(0.90-1.00)$ & $100 \%$ & $62.5 \%(0.21-1.00)$ & $88.4(0.78-0.99)$ \\
\hline 3 years & $77.2 \%(0.43-1.00)$ & $*$ & $*$ & $67.2 \%(0.36-0.99)$ \\
\hline Median OS & - & - & $1.0(0.45-1.56)$ & - \\
\hline
\end{tabular}

Footnote: ${ }^{*}$ ) final case was censored before this point

Table 5. Studies of Octreotide Analogues in Refractory Recurrent Meningiomas. 


\begin{tabular}{|c|c|c|c|c|c|c|}
\hline $\begin{array}{l}\text { Author, year of } \\
\text { publication }\end{array}$ & $\begin{array}{l}\text { Number of patients and } \\
\text { WHO grade of } \\
\text { meningioma }\end{array}$ & $\begin{array}{l}\text { Median } \\
\text { KPS }\end{array}$ & $\begin{array}{l}\text { PFS6 } \\
(\%)\end{array}$ & $\begin{array}{l}\text { Median } \\
\text { TTP/PFS } \\
\text { (months) }\end{array}$ & $\begin{array}{l}\text { Median } \\
\text { OS } \\
\text { (months) }\end{array}$ & Common Toxicities \\
\hline $\begin{array}{l}\text { Chamberlain } \\
\text { (2007) }\end{array}$ & 16 & \multirow[t]{2}{*}{80} & \multirow[t]{2}{*}{44} & \multirow[t]{2}{*}{5} & \multirow[t]{2}{*}{7.5} & \multirow[t]{2}{*}{ Diarrhea } \\
\hline $\begin{array}{l}\text { Sandostatin } \\
\text { LAR [14] }\end{array}$ & $(I, n=8 ; I I, n=3 ; I I I, n=5)$ & & & & & \\
\hline \multirow{2}{*}{$\begin{array}{l}\text { Johnson } \\
\text { (2011) }\end{array}$} & Meningioma:11 & \multirow[t]{3}{*}{ ND } & \multirow[t]{3}{*}{ ND } & \multirow[t]{3}{*}{4.25} & \multirow[t]{3}{*}{32.4} & \multirow{3}{*}{$\begin{array}{l}\text { Diarrhea, anorexia, nausea, } \\
\text { transaminitis }\end{array}$} \\
\hline & $(I, n=3 ; I I, n=3 ; I I I, n=5)$ & & & & & \\
\hline $\begin{array}{l}\text { Sandostatin } \\
\text { LAR [15] }\end{array}$ & Hemangiopericytoma: 1 & & & & & \\
\hline Schulz (2011) & 13 & \multirow[t]{2}{*}{ ND } & \multirow[t]{2}{*}{ ND } & \multirow[t]{2}{*}{24} & \multirow[t]{2}{*}{ ND } & \multirow{2}{*}{$\begin{array}{l}\text { Well tolerated, } n=1 \text { psychiatric side } \\
\text { effects }\end{array}$} \\
\hline $\begin{array}{l}\text { Sandostatin } \\
\text { LAR [16] }\end{array}$ & $\begin{array}{l}(\mathrm{l}, \mathrm{n}=8 \text { localized to skull } \\
\text { base that underwent } \\
\text { analysis) }\end{array}$ & & & & & \\
\hline Simo (2014) & 9 & \multirow[t]{2}{*}{80} & \multirow[t]{2}{*}{44.4} & \multirow[t]{2}{*}{4.23} & \multirow[t]{2}{*}{18.7} & \multirow[t]{2}{*}{ Diarrhea } \\
\hline Octreotide [20] & (II, n=5; III, n=4) & & & & & \\
\hline Norden (2015) & 28 & \multirow[t]{2}{*}{85} & \multirow[t]{2}{*}{32} & \multirow[t]{2}{*}{4.5} & \multirow{2}{*}{$\begin{array}{l}\text { Not } \\
\text { achieved }\end{array}$} & \multirow{2}{*}{$\begin{array}{l}\text { Hyperglycemia, hypoglycemia, elevated } \\
\text { amylase, elevated lipase, fatigue, } \\
\text { hypokalemia }\end{array}$} \\
\hline $\begin{array}{l}\text { Pasireotide } \\
\text { LAR } \\
\text { (SOM230C) } \\
{[21]}\end{array}$ & $(\mathrm{I}, \mathrm{n}=16 ; \mathrm{II} / \mathrm{III} \mathrm{n}=18)$ & & & & & \\
\hline \multirow[t]{2}{*}{ Our study } & 44 & \multirow[t]{2}{*}{80} & \multirow[t]{2}{*}{80.6} & \multirow[t]{2}{*}{35.52} & \multirow{2}{*}{$\begin{array}{l}\text { Not } \\
\text { achieved }\end{array}$} & \multirow[t]{2}{*}{ Diarrhea, headache } \\
\hline & $(I, n=32 ; I I, n=5, I I I n=6)$ & & & & & \\
\hline
\end{tabular}

Table 6. Targeted Therapy for Progressive Recurrent Meningiomas. 


\begin{tabular}{|c|c|c|c|c|c|c|c|c|c|}
\hline $\begin{array}{l}\text { Author, year } \\
\text { of } \\
\text { publication }\end{array}$ & Inhibitor & Target & $\mathrm{N}$ & $\begin{array}{l}\text { Tumor } \\
\text { Grade }\end{array}$ & $\begin{array}{l}\text { Median } \\
\text { KPS }\end{array}$ & $\begin{array}{l}\text { PFS6 } \\
(\%)\end{array}$ & $\begin{array}{l}\text { Median } \\
\text { TTP/PFS } \\
\text { (months) }\end{array}$ & Common Toxicities & $\begin{array}{l}\text { Grade } \\
4 \text { or } 5 \\
\text { toxicity }\end{array}$ \\
\hline $\begin{array}{l}\text { Nayak } \\
(2012) \text { [26] }\end{array}$ & Bevacizumab & VEGF & 15 & $\|\| I$, & ND & 43.7 & 6.5 & $\begin{array}{l}\text { Fatigue, cerebral } \\
\text { hemorrhage }\end{array}$ & No \\
\hline $\begin{array}{l}\text { Lou (2012) } \\
\text { [27] }\end{array}$ & Bevacizumab & VEGF & 14 & I, II, III & 80 & 85.7 & 17.9 & $\begin{array}{l}\text { Thrombocytopenia, } \\
\text { proteinuria, } \\
\text { craniotomy site } \\
\text { cellulitis }\end{array}$ & Yes \\
\hline $\begin{array}{l}\text { Nunes } \\
(2013) \text { [28] }\end{array}$ & Bevacizumab & VEGF & 15 & NF2 & ND & 85 & 15 & $\begin{array}{l}\text { Hypertension, } \\
\text { transaminitis, } \\
\text { menorrhagia, } \\
\text { irregular menses }\end{array}$ & No \\
\hline $\begin{array}{l}\text { Alanin } \\
\text { (2015) [29] }\end{array}$ & Bevacizumab & VEGF & 7 & NF2 & ND & ND & ND & $\begin{array}{l}\text { Intracerebral } \\
\text { hemorrhage }\end{array}$ & Yes \\
\hline \multirow{2}{*}{$\begin{array}{l}\text { Shih (2016) } \\
\text { [23] }\end{array}$} & \multirow[t]{2}{*}{ Bevacizumab+everolimus } & VEGF & \multirow[t]{2}{*}{17} & \multirow[t]{2}{*}{$\mathrm{I}, \mathrm{Il}, \mathrm{III}$} & \multirow[t]{2}{*}{ ND } & \multirow[t]{2}{*}{69} & \multirow[t]{2}{*}{22} & \multirow{2}{*}{$\begin{array}{l}\text { Colitis, chronic } \\
\text { thrombotic } \\
\text { microangiopathy, } \\
\text { proteinuria, } \\
\text { nephrotic syndrome }\end{array}$} & \multirow[t]{2}{*}{ No } \\
\hline & & mTOR & & & & & & & \\
\hline $\begin{array}{l}\text { Wen (2009) } \\
\text { [30] }\end{array}$ & Imatinib & PDGFR & 23 & $\mathrm{I}, \mathrm{I}, \mathrm{III}$ & 80 & 29.4 & 2 & $\begin{array}{l}\text { Anemia, } \\
\text { leukopenia, } \\
\text { neutropenia, } \\
\text { dehydration, } \\
\text { dizziness, } \\
\text { hypophosphatemia }\end{array}$ & Yes \\
\hline $\begin{array}{l}\text { Horak } \\
\text { (2012) [31] }\end{array}$ & Imatinib & PDGFR & 9 & $\mathrm{I}, \mathrm{I}, \mathrm{III}$ & ND & 66.7 & 17 & ND & ND \\
\hline $\begin{array}{l}\text { Reardon } \\
(2012) \text { [32] }\end{array}$ & Imatinib + hydroxyurea & PDGFR & 21 & $\mathrm{I}, \mathrm{Il}, \mathrm{II}$ & ND & 61.9 & 7 & $\begin{array}{l}\text { Anemia, } \\
\text { constipation, } \\
\text { edema, fatigue, } \\
\text { hypoalbuminemia, } \\
\text { hypophosphatemia, } \\
\text { rash, neutropenia, } \\
\text { thrombocytopenia }\end{array}$ & Yes \\
\hline $\begin{array}{l}\text { Raizer } \\
\text { (2014) [33] }\end{array}$ & Valatinib & VEGFR & 25 & $\mathrm{I}, \mathrm{II}, \mathrm{II}$ & 80 & 54.4 & 7.6 & $\begin{array}{l}\text { Fatigue, } \\
\text { hypertension, } \\
\text { transaminitis }\end{array}$ & Yes \\
\hline \multirow{2}{*}{$\begin{array}{l}\text { Kaley (2015) } \\
\text { [34] }\end{array}$} & \multirow[t]{2}{*}{ Sunitinib } & VEGF & \multirow[t]{2}{*}{36} & \multirow[t]{2}{*}{ II, III } & \multirow[t]{2}{*}{80} & \multirow[t]{2}{*}{42} & \multirow[t]{2}{*}{5.2} & \multirow{2}{*}{$\begin{array}{l}\text { Leukopenia, } \\
\text { fatigue, } \\
\text { thrombocytopenia }\end{array}$} & \multirow[t]{2}{*}{ Yes } \\
\hline & & PDGF & & & & & & & \\
\hline $\begin{array}{l}\text { Norden } \\
\text { (2010) [35] }\end{array}$ & Ernotinib/gefitinib & EGFR & 25 & I, II, III & 90 & 28 & 10 & Diarrhea, rash & No \\
\hline $\begin{array}{l}\text { Chamberlain } \\
\text { (2008) [36] }\end{array}$ & Interferon alpha & VEGF & 35 & 1 & 80 & 54 & 7 & $\begin{array}{l}\text { Fatigue, anemia, } \\
\text { leukopenia }\end{array}$ & Yes \\
\hline $\begin{array}{l}\text { Chamberlain } \\
\text { (2013) [37] }\end{array}$ & Interferon alpha & VEGF & 35 & II, III & 80 & 17 & 3 & Fatigue, anemia & No \\
\hline Our study & Samatostatin LAR & sstr & 44 & I, II, III & 80 & 80.6 & 35.52 & Diarrhea, headache & No \\
\hline
\end{tabular}

\section{Figures}




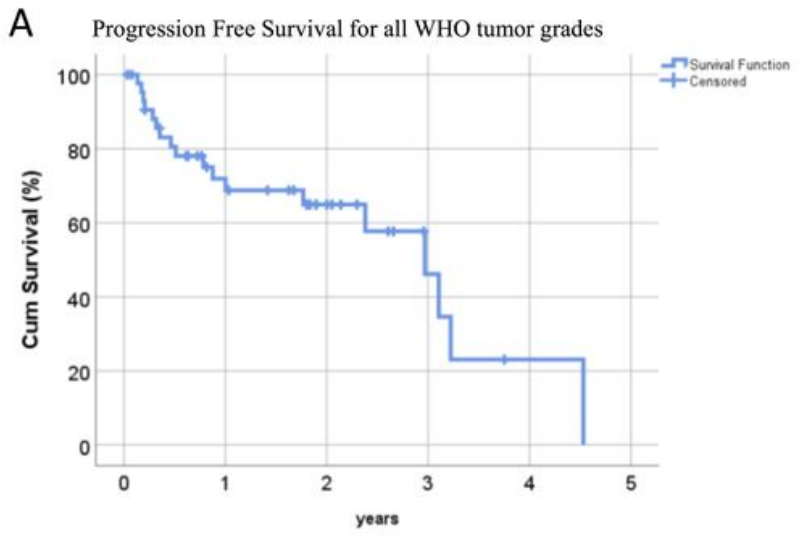

B Progression Free Survival by WHO tumor grade
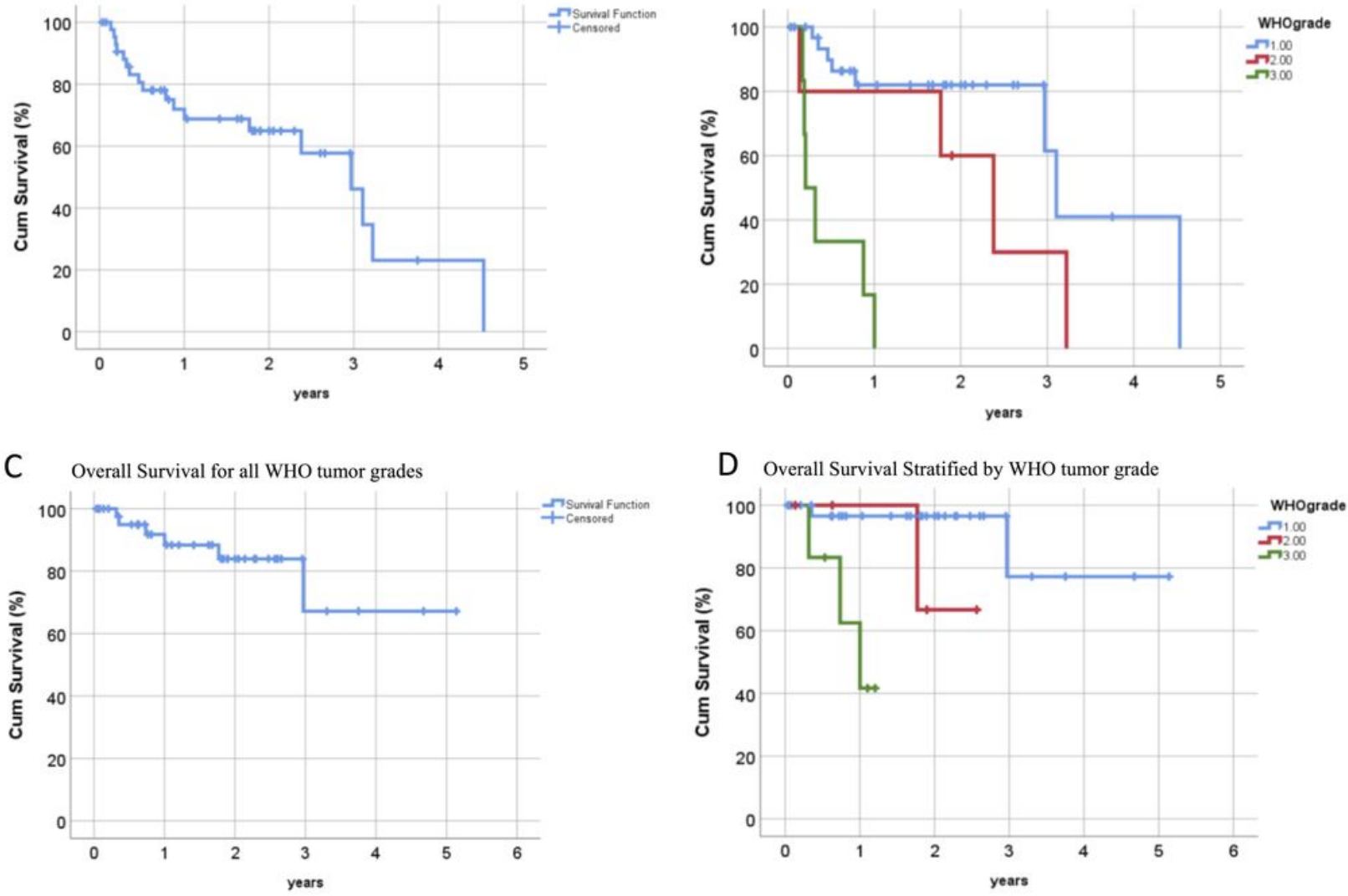

\section{Figure 1}

Figure 1. A) Kaplan-Meier plot demonstrating progression free survival for all WHO tumor grades. B) Kaplan-Meier plot demonstrating progression free survival by WHO tumor grade. C) Kaplan-Meier plot demonstrating overall survival for all WHO tumor grades. D KaplanMeier plot demonstrating overall survival by WHO tumor grades.

\section{Supplementary Files}

This is a list of supplementary files associated with this preprint. Click to download.

- HrachovalmportanceStudy.docx 